\title{
Changes in Retina Practice Patterns During the COVID-19 Pandemic in the Philippines
}

\author{
Albert John Bromeo (D) \\ Patricia Grulla-Quilendrino' \\ Sweet Jorlene Lerit' \\ Myron Carlo Gomez' \\ Cheryl A Arcinue ${ }^{1,2}$ \\ Ralph Anthony De Jesus' \\ Amadeo Veloso Jnr ${ }^{\prime}$

\begin{abstract}
'Asian Eye Institute, Makati, Philippines; ${ }^{2}$ Department of Ophthalmology and Visual Sciences, Philippine General Hospital, University of the Philippines Manila, Manila, Philippines
\end{abstract}

\begin{abstract}
Purpose: The aim of this study was to assess the changes in clinical practice patterns among retina specialists in the Philippines in response to the coronavirus disease 2019 (COVID-19) pandemic.
\end{abstract}

Materials and Methods: This was a multi-center cross-sectional study based on a selfreported online survey. An online questionnaire was distributed among practicing retina specialists in the Philippines as listed in the database of the Vitreo-Retina Society of the Philippines using a combination of convenience and snowball sampling. The questionnaire contained questions regarding changes in clinic set-up, laser procedures, intravitreal injections, vitreoretinal surgery, and long-term outlooks.

Results: A total of 48 responses were recorded and analyzed with a view rate of $41.7 \%$. There was a decrease in the number of clinic consults, laser procedures, intravitreal injections, and vitreoretinal procedures with most reporting only $1-25 \%$ of their usual patient load. Several modifications in clinic protocols have been made, including use of personal protective equipment, adjustments in clinic hours, and scheduling of only urgent cases. The adjustments implemented during the pandemic are expected by most respondents to be longterm changes.

Conclusion: Retina specialists in the Philippines have implemented changes in their practices to combat COVID-19, following guidelines issued by the local and international governing bodies on health.

Keywords: COVID-19, pandemic, practice patterns, retina, vitreoretinal surgery

\section{Introduction}

Coronavirus disease 2019 (COVID-19) is a novel infection first reported in December 2019 and has since become a pandemic that has affected millions of people worldwide. ${ }^{1}$ It is caused by the severe acute respiratory syndrome coronavirus 2 (SARS-CoV-2), an enveloped single-stranded RNA virus. The virus has a high rate of transmission and causes a potentially lethal infection, especially among high-risk individuals, such as immunocompromised individuals, diabetics, those with underlying respiratory disease, and the elderly. ${ }^{2}$ The disease burden of COVID-19 has strained health care systems worldwide, which in turn have brought about various strategies in an effort to control the burden of disease (ie "flatten the curve"). ${ }^{3}$

The concerted and focused effort of health care systems on the COVID-19 pandemic has affected health care strategies for other medical conditions. The impact on the practice of ophthalmology is particularly challenging for those specializing in vitreous and retinal diseases. The diagnosis of retinal diseases
Correspondence: Albert John Bromeo Asian Eye Institute, 9th Floor, PHINMA Plaza, Rockwell Center, Makati, Philippines

Tel + 630288982020

Email albert.bromeo@gmail.com 
requires careful examination using slit-lamp biomicroscopy and/or indirect ophthalmoscopy. ${ }^{4}$ Most retina specialists would routinely order tests such as fundus photography, fluorescein angiography, and optical coherence tomography to aid in their decision-making. ${ }^{4}$ The treatment of retinal diseases with timely laser procedures and/or intravitreal injections are made difficult. Lastly, decisions on whether to delay or push through with urgent surgical cases wherein delayed management may lead to irreversible vision loss, such as those with rhegmatogenous retinal detachment, are made complicated in the current situation. ${ }^{5}$

There is interest in how retina specialists cope with the current climate. ${ }^{6}$ Sharing how different retina specialists have adapted to this difficult time may help other retina specialists in their decision-making and practice patterns. Furthermore, this study may also give some insight on the repercussions of the COVID-19 pandemic on retina practices in the future to prepare retina specialists for "the new normal".

The objective of this study is to determine the changes in practice patterns among retina specialists in the Philippines during the COVID-19 pandemic.

\section{Materials and Methods}

This was a multi-center cross-sectional study based on a self-reported online survey. This study was approved by the St. Cabrini Medical Center/Asian Eye Institute Ethics Review Committee. This research adhered to the tenets of the Declaration of Helsinki.

\section{Survey Questionnaire Design}

The survey design and strategies to enroll retina specialists for optimal participation were discussed prior to implementation of this study. The main instrument was an online questionnaire administered through Google Forms, available at https://forms.gle/hxXrZQaKXjDdYQvHA. The survey did not ask for any identifiable personal details from the respondents. The survey questions were developed to collect information regarding changes in retina practice patterns. It was divided into 6 sections, namely social demographics, changes in clinical set-up, changes in laser procedures, changes in intravitreal injection procedures, changes in vitreoretinal surgery, and expected longterm changes. There were a total of 47 questions. A submission was considered only upon completion of the survey.

\section{Participant Recruitment and Survey Administration}

The participants included retina specialists currently in the database of the Vitreo-Retina Society of the Philippines. Convenience sampling and snowball sampling were used to ensure maximum participation. Responses were collected throughout the month of May 2020. The questionnaire was distributed through email as well as through social media platforms, such as Facebook, Viber, and WhatsApp. The first part of the questionnaire contained the informed consent containing information regarding the purpose, length, and anonymity of the study. Each participant was required to give their consent by clicking on a tick box signifying that they agreed to participate in the study followed by an electronic signature before proceeding.

\section{Statistical Analysis}

The survey response rates were assessed as view rate, participation rate, and completion rate following recommendations given by the Checklist for Reporting Results of Internet E-Surveys (CHERRIES) for the whole study cohort. ${ }^{5}$ Proportions were used to describe categorical data. Statistical tests were not employed since no statistical analysis could be made as no comparison between groups was made in the study. The analysis was done using IBM SPSS for Windows, v. 21.0 (IBM Corp., Armonk, NY, USA).

\section{Results}

A total of 48 submissions were recorded out of 115 to whom the survey link was sent (view rate of $41.7 \%$ ). All participants gave consent, and all had complete responses and were thus included in the analysis.

\section{Socio-Demographic Characteristics of Participating Retina Specialists}

The socio-demographic characteristics of the participants are given in Table 1 . The majority (39.6\%) of participants were between the ages of 31 and 40 years, with slightly more male $(54.2 \%)$ versus female $(45.8 \%)$ participants. The majority $(50 \%)$ declared a predominant practice in the National Capital Region of the Philippines. Most participants $(45.8 \%)$ have been practicing as a retina specialist for more than 10 years. Lastly, the majority (54.2\%) of respondents classified their type of practice as privateindividual practices. 
Table I Socio-Demographic Characteristics of the Participating Retina Specialists

\begin{tabular}{|c|c|c|}
\hline \multicolumn{2}{|l|}{ Characteristic } & \multirow{5}{*}{$\begin{array}{l}\text { n (\%) } \\
19(39.6 \%) \\
13(27.1 \%) \\
12(25 \%) \\
4(8.3 \%)\end{array}$} \\
\hline Age & $31-40$ & \\
\hline & $4 I-50$ & \\
\hline & $5 I-60$ & \\
\hline & $6 I-70$ & \\
\hline \multirow[t]{2}{*}{ Sex } & Male & $26(54.2 \%)$ \\
\hline & Female & $22(45.8 \%)$ \\
\hline \multirow[t]{11}{*}{ Place of Practice in the Philippines } & National Capital Region & $24(50 \%)$ \\
\hline & Region I (llocos Region) & I (2.l\%) \\
\hline & CAR (Cordillera Administrative Region) & I (2.l\%) \\
\hline & Region III (Central Luzon) & $8(16.7 \%)$ \\
\hline & Region IVA (CALABARZON) & $3(6.3 \%)$ \\
\hline & Region IVB (Southwestern Tagalog Region) & $2(4.2 \%)$ \\
\hline & Region VI (Western Visayas) & $2(4.2 \%)$ \\
\hline & Region VII (Central Visayas) & $4(8.3 \%)$ \\
\hline & Region VIII (Eastern Visayas) & $3(6.3 \%)$ \\
\hline & Region XI (Davao Region) & I (2.I\%) \\
\hline & Region XII (Soccskarsargen) & $\mathrm{I}(2.1 \%)$ \\
\hline \multirow[t]{4}{*}{ Years of Practice } & Less than I & $4(8.3 \%)$ \\
\hline & I to 5 & $9(18.8 \%)$ \\
\hline & 5 to 10 & $13(27.1 \%)$ \\
\hline & More than 10 & $22(45.8 \%)$ \\
\hline \multirow[t]{4}{*}{ Type of Practice } & Private - individual & $26(54.2 \%)$ \\
\hline & Private - joint (ie group practice) & $15(31.3 \%)$ \\
\hline & Government - employee & $6(12.5 \%)$ \\
\hline & Medical college/academe & $\mathrm{I}(2.1 \%)$ \\
\hline
\end{tabular}

\section{Changes in Clinic Set-Up}

Amid the ongoing pandemic, the respondents still performed a number of clinical services, albeit not at full capacity (Figure 1). Only $47.9 \%$ of respondents still see new patient consults, while slightly more $(62.5 \%)$ see referred patient consults. For follow-up patient consults, $75 \%$ still see postoperative follow-up patients, while only $22.9 \%$ see routine follow-up patients. The number of respondents performing a variety of vitreoretinal procedures has also changed as only $20.8 \%$ perform elective retina surgeries, and only $72.9 \%$ perform emergency retina surgeries. The number of respondents performing intravitreal injections and laser procedures has also decreased, with only $58.3 \%$ and $56.3 \%$ performing the procedures, respectively. In addition, $10.4 \%$ of respondents said that they do not perform any clinical services at the current time.

As a corollary to the decreased capacity of clinical services, only $85.4 \%$ of respondents affirmed to performing physical or face-to-face consultations. Telemedicine has emerged as a promising way of delivering clinical services during the current time, as $62.5 \%$ of respondents affirmed to holding teleconsultations. The proportion of consultations that were physical as compared to teleconsults were varied, with the majority $(37.5 \%)$ indicating that $76-100 \%$ of their consults were still physical, followed by $1-25 \%$ in $22.9 \%, 26-50 \%$ in $14.6 \%$, and $51-75 \%$ in $12.5 \%$. Teleconsults comprised the only consultation method for $12.5 \%$ of respondents. The platform for teleconsultations varied, with the majority $(72.9 \%)$ of respondents using instant messaging apps, such as Viber, Messenger, and WhatsApp. Other platforms used by respondents included telephone (37.5\%), customized websites $(33.3 \%)$, video conferencing apps, such as Zoom $(20.8 \%)$ and e-mail (14.6\%).

For respondents performing physical consultations, a number of changes were noted (Table 2). Scheduling of consultations seemed to be important as the majority 


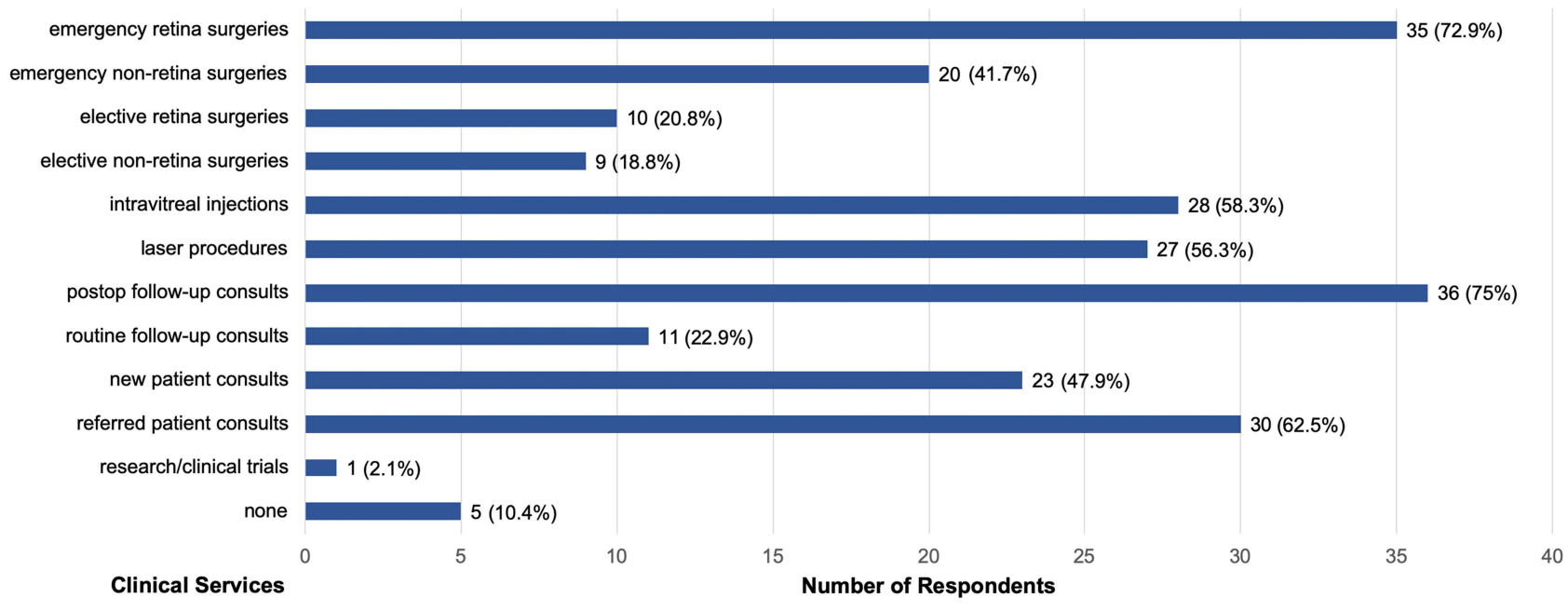

Figure I Clinical services performed by vitreoretinal specialists in the Philippines during the COVID-I9 Pandemic.

(58.3\%) indicated that they only saw patients with scheduled appointments. About $12.5 \%$ still also saw walk-in patients along with those with appointments, while $18.8 \%$ saw patients but with redacted clinic hours. A significant majority (81.3\%) screened patients for symptoms of COVID-19, travel history, or contact with COVID-19 patients.

While holding clinic, measures that have been taken to protect medical staff included working in separate teams $(18.8 \%)$, performing alternative work such as research and education (10.4\%), use of personal protective equipment (PPE) (60\%), and reduced work hours (75.6\%). During the duration of their stay in the clinic, measures advised to patients included handwashing with soap and water (37.5\%), hand disinfection with alcohol or other disinfectants $(83.3 \%)$, footwear disinfection (45.8\%), physical distancing $(72.9 \%)$, wearing a face mask $(89.6 \%)$, wearing gloves (20.8\%), and wearing goggles (14.6\%). When holding clinic, various PPE were used by the respondents (Figure 2). The most commonly used PPE were N95 masks $(70.8 \%)$, gloves $(66.7 \%)$, eye goggles $(60.4 \%)$, surgical masks (56.3\%), and face shields (56.3\%). In addition, physical changes in the clinic included placement of a slit-lamp barrier or breath shield (87.5\%), placement of a barrier over the indirect ophthalmoscope (31.3\%), disinfection of the clinic after every patient (87.5\%), and use of room air controllers $(29.2 \%)$.

Some vitreoretinal cases deemed by the respondents to be urgent enough to warrant in-office care during the time included retinal holes or breaks $(100 \%)$, retinopathy of prematurity (93.8\%), retinal artery occlusion (83.3\%), retinal vein occlusion $(81.3 \%)$, and diabetic retinopathy $(45.8 \%)$. In terms of symptoms of retinal diseases reported by patients, those deemed urgent included blurring of vision (91.7\%), flashes (79.2\%), visual field loss (79.2\%), eye pain (77.1\%), and metamorphopsia (66.7\%).

The clinical techniques employed by the respondents to examine the retina included slit-lamp biomicroscopy using noncontact lens (77.1\%), slit-lamp biomicroscopy using contact lens (12.5\%), and indirect ophthalmoscopy $(85.4 \%)$. About $12.5 \%$ of respondents indicated that they would forego clinical examination and just order diagnostics, such as fundus photography and optical coherence tomography (OCT).

Even with the numerous precautions started, respondents noted a decrease in patients seen in the clinic (Figure 3A), with the majority $(81.3 \%)$ of respondents indicating that they saw only $1-25 \%$ of their usual clinic patient load, followed by $0 \%$ in $10.4 \%, 26-50 \%$ in $4.2 \%$, $51-75 \%$ in $2.1 \%$, and $75-100 \%$ in $2.1 \%$.

\section{Changes in Laser Procedures}

The number of laser procedures performed by retina specialists (Table 3, Figure 3B) has gone down with the majority $(68.8 \%)$ of respondents indicating that only $1-$ $25 \%$ of their usual number are currently performed, followed by $0 \%$ in $27.1 \%, 51-75 \%$ in $2.1 \%$, and $26-50 \%$ in $2.1 \%$.

PPE was worn by all respondents when performing laser procedures (Figure 2). When asked what PPE the respondents wore, the most recurring responses included N95 masks (70.8\%), eye goggles (66.7\%), gloves (62.5\%), 
Table 2 Changes in Clinic Set-Up and Consultations

\begin{tabular}{|c|c|c|}
\hline Query & Response & n (\%) \\
\hline Percentage of Usual Clinic Load Seen & $\begin{array}{l}0 \% \\
I-25 \% \\
26-50 \% \\
5 I-75 \% \\
76-100 \%\end{array}$ & $\begin{array}{l}5(10.4 \%) \\
39(81.3 \%) \\
2(4.2 \%) \\
\text { I }(2.1 \%) \\
I(2.1 \%)\end{array}$ \\
\hline Scheduling of Clinic Consults & $\begin{array}{l}\text { Both walk-in and with appointment consults with usual } \\
\text { work hours } \\
\text { Both walk-in and with appointment consults with } \\
\text { redacted work hours } \\
\text { Strictly with appointment consults only } \\
\text { No clinic }\end{array}$ & $\begin{array}{l}6(12.5 \%) \\
9(18.8 \%) \\
28(58.3 \%) \\
5(10.4 \%)\end{array}$ \\
\hline $\begin{array}{l}\text { Ophthalmic Symptoms Considered Urgent Enough to } \\
\text { Warrant Clinic Consult }\end{array}$ & $\begin{array}{l}\text { Blurring of vision } \\
\text { Visual field loss } \\
\text { Metamorphopsia } \\
\text { Micropsia/macropsia } \\
\text { Floaters } \\
\text { Flashes } \\
\text { Eye pain } \\
\text { Eye redness }\end{array}$ & $\begin{array}{l}44(91.7 \%) \\
38(79.2 \%) \\
32(66.7 \%) \\
22(45.8 \%) \\
27(56.3 \%) \\
38(79.2 \%) \\
37(77.1 \%) \\
25(52.1 \%)\end{array}$ \\
\hline $\begin{array}{l}\text { Retinal Cases Considered Urgent Enough to Warrant Clinic } \\
\text { Consult }\end{array}$ & $\begin{array}{l}\text { Diabetic retinopathy } \\
\text { Retinal vein occlusion } \\
\text { Retinal artery occlusion } \\
\text { Age-related macular degeneration } \\
\text { Central serous retinopathy } \\
\text { Polypoidal choroidal vasculopathy } \\
\text { Pathologic myopia } \\
\text { Retinal breaks and/or retinal detachment } \\
\text { Retinopathy of prematurity }\end{array}$ & $\begin{array}{l}22(45.8 \%) \\
39(81.3 \%) \\
40(83.3 \%) \\
14(29.2 \%) \\
5(10.4 \%) \\
25(52.1 \%) \\
2(4.2 \%) \\
48(100 \%) \\
45(93.8 \%)\end{array}$ \\
\hline
\end{tabular}

surgical masks (41.7\%), and surgical gowns (35.4\%). Common measures that have been implemented in the laser procedure area included disinfection of the laser room after each patient $(79.2 \%)$ and placement of a slitlamp barrier or breath shield (77.1\%).

The conditions deemed by the respondents to be urgent enough to warrant scheduling of laser procedures during the time were varied, but the top responses included focal laser treatment for retinal tears, holes, or other breaks $(97.9 \%)$, focal laser treatment for subclinical retinal detachment (72.9\%), panretinal photocoagulation for diabetic retinopathy $(68.8 \%)$, focal laser treatment for central retinal vein occlusion $(54.2 \%)$, and focal laser treatment for branch retinal vein occlusion $(39.6 \%)$.

With regard to panretinal photocoagulation, the majority $(72.9 \%)$ of respondents indicated that they would complete the laser in one session if able to. The statement was not echoed in $18.8 \%$ of respondents, while $8.3 \%$ were undecided at the time.

In the follow-up of postlaser patients, $54.2 \%$ of respondents followed-up within 1 month, followed by within a week in $29.2 \%$, and as needed if with problems in $16.7 \%$.

\section{Changes in Intravitreal Injections}

The number of intravitreal injections performed by retina specialists (Table 4, Figure 3C) has also gone down. Half of the respondents indicated that only $1-25 \%$ of their usual number were performed, followed by $0 \%$ in $37.5 \%, 51-$ $75 \%$ in $8.3 \%, 26-50 \%$ in $2.1 \%$, and $76-100 \%$ in $2.1 \%$. PPE was again worn by all respondents when performing intravitreal injections (Figure 2). When asked what PPE the respondents wore, the most recurring responses included N95 mask (72.9\%), eye goggles (72.9\%), gloves (68.8\%), surgical cap (64.6\%), and surgical gown (52.1\%). 


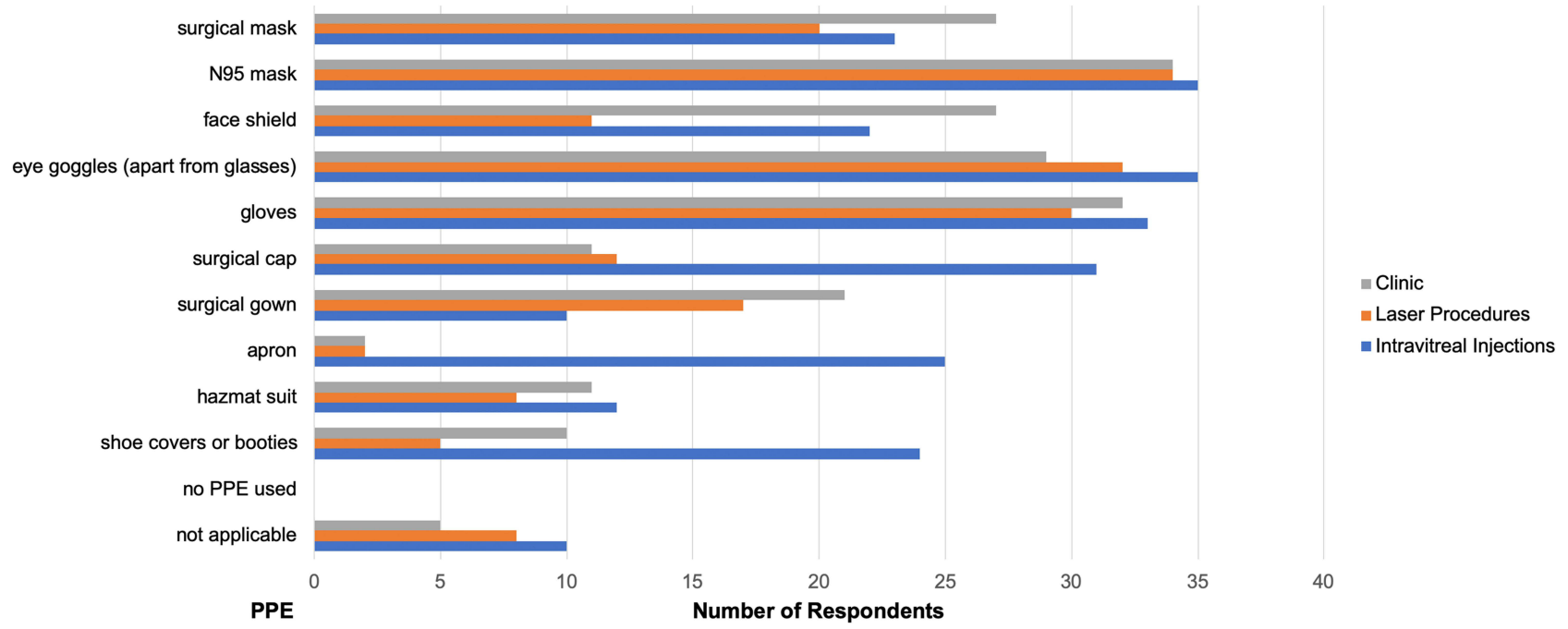

Figure 2 Personal protective equipment (PPE) used by vitreoretinal specialists in the Philippines during the COVID-19 pandemic for clinic, laser procedures, and intravitreal injections.

The climate of the COVID-19 pandemic has resulted in changes in consultation patterns with regard to patients already undergoing routine intravitreal anti-VEGF injection, with the majority $(29.2 \%)$ of respondents indicating that they would forego face-to-face consultations and just do diagnostics, such as fluorescein angiography and OCT, followed by $22.9 \%$, which would still do a face-to-face consult along with diagnostics, $10.4 \%$, which would just to a face-to -face consult and forego diagnostics, while another $10.4 \%$, which would do a telemedicine consult. About $12.5 \%$ of respondents would forego any consultation at all and just proceed directly with the intravitreal injection based on the patient's historical injection schedule.

The pandemic has also inevitably affected the injection schedule of these patients and has forced retina specialists to adapt to certain changes. In patients being treated for diabetic macular edema, $37.5 \%$ deferred injections until further notice, $39.6 \%$ continued injections but at a longer interval, and $12.5 \%$ continued with the usual injection schedule. There were similar practices noted for patients being treated for macular edema from retinal vein occlusion, as $35.4 \%$ deferred injections until further notice, $33.3 \%$ continued injections but at a longer interval, and $20.8 \%$ continued with the usual injection schedule. The results were more varied regarding patients being treated for neovascular age-related macular degeneration, as $18.8 \%$ deferred injections until further notice, another $18.8 \%$ switched to a pro re nata (PRN) schedule, $14.6 \%$ switched to a treat-and-extend schedule, $16.7 \%$ switched to a treat-andextend schedule but used the maximum interval, and $16.7 \%$ continued with the usual injection schedule.
In the follow-up of postinjection patients, $52.1 \%$ of respondents would follow up after 1 month or whenever the next injection is due, $20.8 \%$ would follow up within 1 month, $16.7 \%$ would follow up within 1 week, and $10.4 \%$ would follow up a day after.

\section{Changes in Vitreoretinal Surgeries}

The number of vitreoretinal surgeries performed by the respondents (Table 5, Figure 3D) saw a significant downward trend, with $52.1 \%$ indicating that they perform only $1-25 \%$ of their usual number of procedures, $39.6 \%$ indicating that they perform no procedures, and $8.3 \%$ indicating that they perform only $26-50 \%$.

The conditions deemed by the respondents to be urgent enough to warrant surgery during the time were varied, with the most responses for endophthalmitis (97.9\%), macula-on rhegmatogenous retinal detachment $(93.8 \%)$, ocular trauma (91.7\%), retinopathy of prematurity $(81.3 \%)$, and maculaoff rhegmatogenous retinal detachment (66.7\%).

Changes made to the operating room set-up included limiting the number of staff entering and exiting the room $(68.8 \%)$, disinfection of the room after each procedure (64.6\%), use of room air controllers (29.2\%), placement of a transparent shield over the microscope (22.9\%), and setting-up a physical barrier between the surgeon and the patient (eg a transparent curtain or box) (12.5\%). PPE, in addition to the usual surgical attire, was worn by all respondents who performed surgery, which included N95 masks (79.2\%), eye goggles (75\%), surgical booties $(58.3 \%)$, hazmat suits $(50 \%)$, and face shields $(27.1 \%)$. 


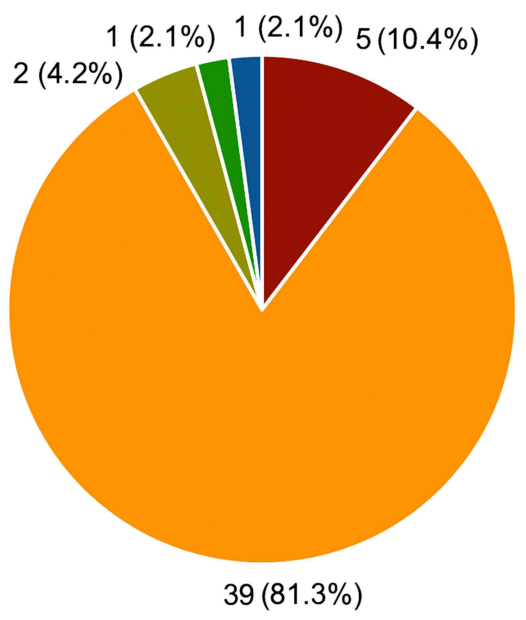

\section{A Clinic}

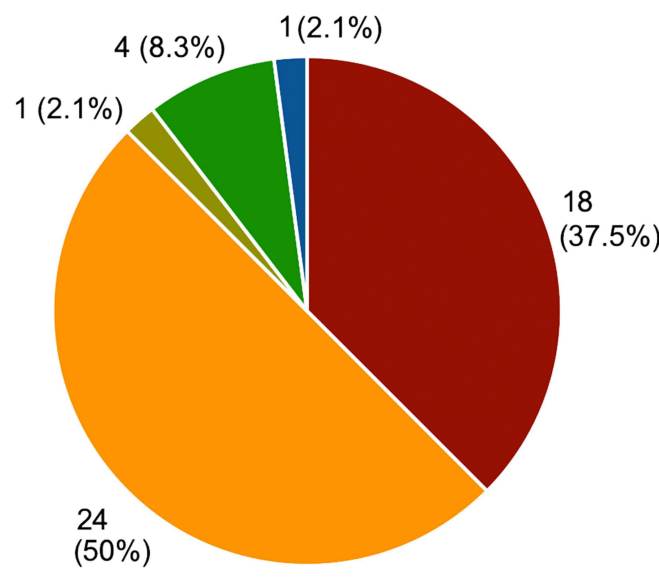

C Intravitreal injections

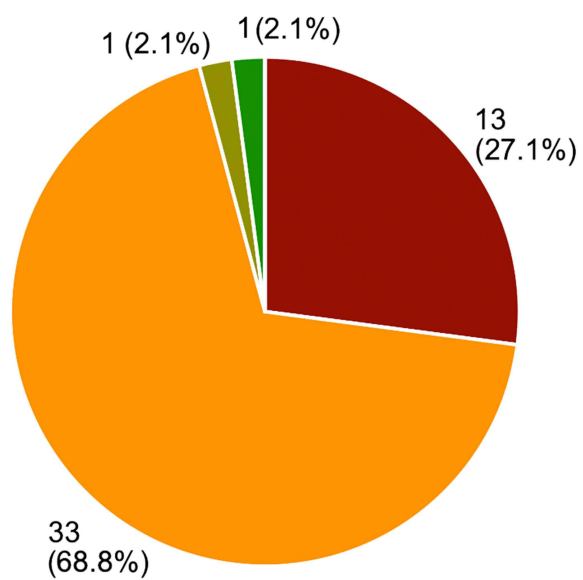

B Laser Procedures

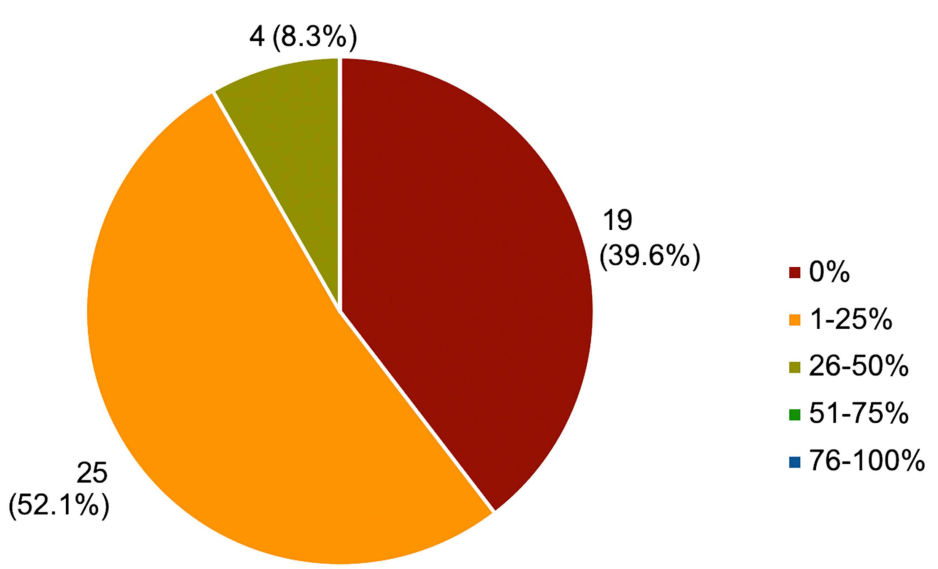

D Vitreoretinal Surgeries

Figure 3 Estimated number of patients during the COVID-19 pandemic of vitreoretinal specialists in the Philippines compared to their usual patient load for (A) clinical consults, (B) laser procedures, (C) intravitreal injections, and (D) vitreoretinal surgeries.

The sentiment of the majority $(62.5 \%)$ of respondents regarding wearing PPE during surgery is that it affects their surgical performance, but they will wear it regardless, followed by $20.8 \%$ who said that they will probably consider removing some PPE intraoperatively to improve their surgical performance and $8.3 \%$ who said that wearing PPE does not affect their surgical performance.

When asked regarding their sentiments regarding the mode of anesthesia to be used during surgery, $37.5 \%$ would still prefer general anesthesia, 29.2\% would avoid general anesthesia, if possible, and just perform the surgery under local anesthesia, 22.9\% would switch from general anesthesia to IV sedation, and $10.4 \%$ would defer to the anesthesiologist.
About 58.3\% of respondents indicated that they would require a negative COVID-19 diagnostic test prior to performing surgery, $12.5 \%$ did not, and $29.2 \%$ were undecided. In addition, when asked what to do when a patient scheduled for urgent retinal surgery develops COVID-19 in the interim period before surgery, 70.8\% would defer surgery until with a COVID-19 negative test result, $18.8 \%$ would go ahead with the surgery but with necessary precautions, and $6.3 \%$ would refer to an institution that caters to COVID-19 patients.

In the follow-up of postoperative patients, $54.2 \%$ of respondents would follow up the day after, $41.7 \%$ would follow up within 1 week, 2.1\% would follow up within 1 month, and another $2.1 \%$ would follow up as needed if with problems. 
Table 3 Changes in Laser Procedures

\begin{tabular}{|c|c|c|}
\hline Query & Response & n (\%) \\
\hline Percentage of Usual Number of Laser Procedures Still Performed & $\begin{array}{l}0 \% \\
I-25 \% \\
26-50 \% \\
5 I-75 \% \\
76-100 \%\end{array}$ & $\begin{array}{l}\text { I3 }(27.1 \%) \\
33(68.8 \%) \\
\text { I }(2.1 \%) \\
\text { I }(2.1 \%) \\
0(0 \%)\end{array}$ \\
\hline Laser Procedures Considered Urgent Enough to Warrant Scheduling & $\begin{array}{l}\text { PRP for diabetic retinopathy } \\
\text { PRP for central retinal vein occlusion } \\
\text { PRP for branch retinal vein occlusion } \\
\text { PRP for retinopathy of prematurity } \\
\text { FLT for choroidal neovascularization } \\
\text { FLT for central serous chorioretinopathy } \\
\text { FLT for retinal breaks } \\
\text { FLT for subclinical retinal detachment }\end{array}$ & $\begin{array}{l}33(68.8 \%) \\
26(54.2 \%) \\
19(39.6 \%) \\
4(6.3 \%) \\
10(20.8 \%) \\
2(4.2 \%) \\
47(97.9 \%) \\
35(72.9 \%)\end{array}$ \\
\hline Schedule of Follow-Up Visit After Vitreoretinal Surgery & $\begin{array}{l}\text { A day after } \\
\text { Within I week } \\
\text { Within I month } \\
\text { As needed if with problems }\end{array}$ & $\begin{array}{l}0(0 \%) \\
8(16.7 \%) \\
26(54.2 \%) \\
14(29.2 \%)\end{array}$ \\
\hline
\end{tabular}

Abbreviations: PRP, panretinal photocoagulation; FLT, focal laser treatment.

\section{Expected Long-Term Changes in Practice}

The outlook of the majority (77.1\%) of respondents was that adjustments to patient flow and care are expected to constitute long-term changes, which will be in place even after the COVID-19 pandemic has passed, while $16.7 \%$ were reserved depending on societal standards and norms, and $6.3 \%$ who said that there will be a return to pre-COVID protocols.

With regard to what the participants thought as the most important factor that will convince them to reopen their clinical practices to non-urgent cases, the responses were mixed. The top responses included government advisory regarding return to normal work $(27.1 \%)$, availability of COVID-19 vaccine (25\%), area of practice having a relatively low and stable incidence of COVID-19 (22.9\%), and mass COVID-19 testing (6.3\%).

Mixed responses were also obtained regarding expectations on the return of their practices to their pre-COVID state, with a slight majority $(31.3 \%)$ expecting this in about a year, followed by more than a year $(25 \%)$, in about 6 months $(20,8 \%)$, in about 3 months $(14.6 \%)$, and do not know yet $(8.3 \%)$.

Lastly, the pandemic has also affected the financial aspect of retina practices as the majority $(66.6 \%)$ of respondents noted that they would adjust their professional fees to offset the costs of non-clinic and other changes in practices, followed by $20.8 \%$ who said that they would not, and $12.5 \%$ who said they do not know yet.

\section{Discussion}

This is the first survey among retina specialists in the Philippines about how the COVID-19 pandemic has affected their clinical practice. The results of the survey can be summarized in 4 main findings: (1) a decrease in the usual patient load, (2) use of various PPE in both the clinic and operating room setting, (3) an increase in the use of telemedicine, and (4) changes in clinical decisionmaking regarding urgency of clinic consults and procedures.

The COVID-19 pandemic has created a precarious situation for the retina practitioner. Since the transmission of COVID-19 occurs because of close contact with an infected individual, those who work in close proximity to such individuals have a greater risk of infection. ${ }^{2}$ The diagnosis and management of retinal diseases depends on accurate clinical evaluation by slit-lamp biomicroscopy, indirect ophthalmoscopy, and additional diagnostics, such as fluorescein angiography and optical coherence tomography. ${ }^{4}$ The distance between the retina specialist and the patient during these examinations is usually less than 1 meter, which puts the retina specialist at risk of contracting COVID-19. Hence, retina specialists needed to find ways to adapt to continue treating patients in the midst of the pandemic. ${ }^{7}$

Retina practices in the Philippines have experienced a massive decrease in the number of patients as a result 
Table 4 Changes in Intravitreal Injections

\begin{tabular}{|c|c|c|}
\hline Query & Response & n (\%) \\
\hline $\begin{array}{l}\text { Percentage of Usual Number of Intravitreal Injections Still } \\
\text { Performed }\end{array}$ & $\begin{array}{l}0 \% \\
I-25 \% \\
26-50 \% \\
5 I-75 \% \\
76-100 \%\end{array}$ & $\begin{array}{l}18(37.5 \%) \\
24(50 \%) \\
\text { I }(2.1 \%) \\
4(8.3 \%) \\
\text { I }(2.1 \%)\end{array}$ \\
\hline $\begin{array}{l}\text { Change in Consultation Pattern for Patients Undergoing } \\
\text { Intravitreal Anti-VEGF Injection }\end{array}$ & $\begin{array}{l}\text { Continue with face-to-face consult and diagnostics } \\
\text { Forego face-to-face consult and just do diagnostics } \\
\text { Do face-to-face consult only and forego diagnostics } \\
\text { Do teleconsult } \\
\text { Forego any consult and proceed directly with injection } \\
\text { Other responses }\end{array}$ & $\begin{array}{l}\text { II }(22.9 \%) \\
\text { I4 (29.2\%) } \\
5(10.4 \%) \\
5(10.4 \%) \\
6(12.5 \%) \\
7(14.6 \%)\end{array}$ \\
\hline $\begin{array}{l}\text { Change in Injection Schedule for Age-Related Macular } \\
\text { Degeneration Patients }\end{array}$ & $\begin{array}{l}\text { Continue with usual injection schedule } \\
\text { Switched to treat-and-extend } \\
\text { Switched to treat-and-extend but used maximum interval } \\
\text { Switched to pro re nata (PRN) } \\
\text { Deferral of injections until further notice } \\
\text { Other responses }\end{array}$ & $\begin{array}{l}8(16.7 \%) \\
7(14.6 \%) \\
8(16.7 \%) \\
9(18.8 \%) \\
9(18.8 \%) \\
7(14.6 \%)\end{array}$ \\
\hline $\begin{array}{l}\text { Change in Injection Schedule for Diabetic Macular Edema } \\
\text { Patients }\end{array}$ & $\begin{array}{l}\text { Continue with usual injection schedule } \\
\text { Continued injections but with longer interval } \\
\text { Deferral of injections until further notice } \\
\text { Other responses }\end{array}$ & $\begin{array}{l}6(12.5 \%) \\
19(39.6 \%) \\
18(37.5 \%) \\
5(10.4 \%)\end{array}$ \\
\hline $\begin{array}{l}\text { Change in Injection Schedule for Retinal Vein Occlusion } \\
\text { Patients }\end{array}$ & $\begin{array}{l}\text { Continue with usual injection schedule } \\
\text { Continued injections but with longer interval } \\
\text { Deferral of injections until further notice } \\
\text { Other responses }\end{array}$ & $\begin{array}{l}10(20.8 \%) \\
16(33.3 \%) \\
17(35.4 \%) \\
5(10.4 \%)\end{array}$ \\
\hline Schedule of Follow-Up Visit After Intravitreal Injection & $\begin{array}{l}\text { A day after } \\
\text { Within I week } \\
\text { Within I month } \\
\text { As needed if with problems }\end{array}$ & $\begin{array}{l}5(10.4 \%) \\
8(16.7 \%) \\
10(20.8 \%) \\
25(52.1 \%)\end{array}$ \\
\hline
\end{tabular}

of the pandemic, with accompanying decreases in laser procedures, intravitreal injections, and vitreoretinal surgeries. Most practices have cancelled outpatient visits and elective procedures, limiting consultations to only urgent and emergent cases. ${ }^{8-10}$ Ophthalmology services have taken a back seat at the moment in favor of other medical specialties at the forefront of the pandemic, with some ophthalmologists rendering emergency medicine services as well. In addition, restrictions imposed by the Philippine government on the mobility of its citizens to prevent spread of infection have also probably contributed to the decreased patient load. ${ }^{9}$

An important facet of ophthalmic clinical care at the time of the COVID-19 pandemic is the use of PPE. ${ }^{11}$ The protection of clinical personnel is paramount since there is risk of infecting other members of the medical team necessary for continuity of care for other patients. Most retina practices have adapted general recommendations, which include hand disinfection, use of masks, and physical distancing in their practices. ${ }^{9-11}$ Some also include screening patients for potential infection through targeted questions regarding symptoms, travel history, and contact history as part of their protocols. When seeing patients and performing procedures, retina specialists have applied various types of equipment to reduce the risk of infection, including N95 masks, gloves, goggles, and surgical gowns. ${ }^{12-14}$ Further protection is afforded by adapting changes in clinic set-up which include placing protective plastic on shields on slit lamps and indirect ophthalmoscopes, various forms of sterilization, and limiting patient contact. ${ }^{9-11}$ The still evolving 
Table 5 Changes in Vitreoretinal Surgeries

\begin{tabular}{|c|c|c|}
\hline Query & Response & n (\%) \\
\hline Percentage of Usual Number of Surgeries Still Performed & $\begin{array}{l}0 \% \\
1-25 \% \\
26-50 \% \\
51-75 \% \\
76-100 \%\end{array}$ & $\begin{array}{l}19(39.6 \%) \\
25(52.1 \%) \\
4(8.3 \%) \\
0(0 \%) \\
0(0 \%)\end{array}$ \\
\hline $\begin{array}{l}\text { Surgical Cases Considered Urgent Enough to Warrant } \\
\text { Scheduling }\end{array}$ & $\begin{array}{l}\text { Macula-on rhegmatogenous retinal detachment } \\
\text { Macula-off rhegmatogenous retinal detachment } \\
\text { Endophthalmitis } \\
\text { Epiretinal membrane and/or macular hole } \\
\text { Diabetic tractional retinal detachment } \\
\text { Vitreous hemorrhage in a diabetic patient } \\
\text { Vitreous hemorrhage in a non-diabetic patient } \\
\text { Dropped cataract } \\
\text { Dropped intraocular lens } \\
\text { Floater removal } \\
\text { Ocular trauma } \\
\text { Retinopathy of prematurity }\end{array}$ & $\begin{array}{l}45(93.8 \%) \\
32(66.7 \%) \\
47(97.9 \%) \\
0(0 \%) \\
12(25 \%) \\
11(22.9 \%) \\
12(25 \%) \\
15(31.3 \%) \\
3(6.3 \%) \\
0(0 \%) \\
44(91.7 \%) \\
39(81.3 \%)\end{array}$ \\
\hline Requiring COVID-Negative Test Prior to Surgery & $\begin{array}{l}\text { Yes } \\
\text { No } \\
\text { Undecided }\end{array}$ & $\begin{array}{l}28(58.3 \%) \\
6(12.5 \%) \\
14(29.2 \%)\end{array}$ \\
\hline Sentiment on How PPE Affects Surgical Performance & $\begin{array}{l}\text { Does not affect surgical performance } \\
\text { Affects surgical performance but will wear anyway } \\
\text { Affects surgical performance and will consider removing it if it } \\
\text { interferes with surgical performance } \\
\text { Not performing surgeries }\end{array}$ & $\begin{array}{l}4(8.3 \%) \\
30(62.5 \%) \\
10(20.8 \%) \\
4(8.3 \%)\end{array}$ \\
\hline $\begin{array}{l}\text { Course of Action if Patient Scheduled for Urgent Vitreoretinal } \\
\text { Surgery Becomes COVID-Positive }\end{array}$ & $\begin{array}{l}\text { Go ahead with surgery with precautions } \\
\text { Defer surgery } \\
\text { Refer to COVID-handling institution } \\
\text { Other responses }\end{array}$ & $\begin{array}{l}9(18.8 \%) \\
34(70.8 \%) \\
3(6.3 \%) \\
2(4.2 \%)\end{array}$ \\
\hline Schedule of Follow-Up Visit After Vitreoretinal Surgery & $\begin{array}{l}\text { A day after } \\
\text { Within I week } \\
\text { Within I month } \\
\text { As needed if with problems }\end{array}$ & $\begin{array}{l}26(54.2 \%) \\
20(41.7 \%) \\
\text { I }(2.1 \%) \\
\text { I }(2.1 \%)\end{array}$ \\
\hline
\end{tabular}

evidence-based studies on the transmission of COVID-19 in routine ophthalmic practice were manifested by the varied methods by which retina specialists have adopted their clinic protocols in order to continue treating patients in a safe environment. ${ }^{5,9,10}$

The fall in the number of face-to-face consultations was accompanied by a rise in the number of telemedicine consultations. While telemedicine cannot function as a complete replacement for face-to-face clinical examination, most retina specialists agree that its utility cannot be undermined during this pandemic. Consultations through telemedicine are particularly useful for screening patients for red flag ophthalmic signs and symptoms to determine which ones truly need a face-to-face consult. ${ }^{15,16}$ The main limitation of retinal telemedicine in the current setting is that most established guidelines still require patients to have retinal imaging done at an eye center - a situation that is difficult in a quarantine setting. The development of home-based retinal imaging is a major limiting factor. ${ }^{17}$

The most concerning issues faced by retina specialists at this time are those of patients needing intravitreal injections. It has been demonstrated in several studies that a delay in therapy results in irreversible vision loss in these patients. ${ }^{5}$ Thus, retina specialists are faced with the 
difficult dilemma of weighing the benefit of injection to their patients' vision with the risk of contracting COVID19. Various aspects of the clinical evaluation pathway (ie slit-lamp examination, OCT imaging) may have been omitted to reduce the chances of transmission. In terms of scheduling, many specialists have adapted by adapting longer intervals of injections or just injecting depending on need. Most difficulties in this aspect have centered around neovascular AMD patients, with DME and RVO patients being more forgiving in terms of requiring a strict injection schedule. $^{5}$ The lack of established clinical guidelines was reflected by the varied responses in this study.

Lastly, it is not surprising that the execution of vitreoretinal surgery during the COVID-19 pandemic was difficult. During surgery, the patient and the vitreoretinal surgeon are in close proximity for a significant period of time, which dramatically increases the chances of possible SARS-CoV-2 transmission. ${ }^{10}$ For this reason, surgery was limited to only the most vision-threatening cases, such as retinal detachment, endophthalmitis, and ocular penetrating injuries. Controversial issues regarding performing surgery at this time included the requirement of a negative COVID-19 test result prior to surgery, scheduling of confirmed COVID-19 positive cases, and adjustments in the mode of anesthesia to prevent potential aerosol generation.

The strength of this study lies in highlighting how retina specialists in the Philippines have adapted to face the challenges of clinical practice during a pandemic. The results highlight the various ways in which patient care can still be delivered despite the threat of COVID-19. Due to the nature of this study, it is prone to some limitations. In order to minimize biases due to social desirability, the survey did not ask for any identifying data and assured the participants on the confidentiality of the data. The survey questionnaire will need to undergo validation if reproducibility studies will be planned. There may be selection bias due to the crosssectional nature of the study and the employed sampling method. Questionnaire bias was addressed by keeping the questions as neutral and simple as possible. Lastly, since the survey only collected a cross-sectional response over a onemonth data collection period, there may be further changes in the practice patterns of the participants due to the rapidly evolving course of the current pandemic.

\section{Conclusion}

The study found that retina specialists in the Philippines implemented various changes in their practices to combat COVID-19. The changes brought about by the pandemic include decreased patient load, use of PPE, increased use of telemedicine, and changes in clinical decision-making for various vitreoretinal conditions. Recommendations and guidelines for clinical practice have been published and are evolving. Retina specialists, as well as other ophthalmologists, may adapt to further changes in their practice as more information about COVID-19 are elucidated and understood. The changes started during this time may have ramifications on the practice of vitreoretinal medicine in the long term.

\section{Acknowledgments}

The authors would like to thank the Asian Eye Institute and the Vitreo-retina Society of the Philippines for their support in accomplishing this study.

\section{Disclosure}

The authors report no conflicts of interest in this work.

\section{References}

1. Huang C, Wang Y, Li X, et al. Clinical features of patients infected with 2019 novel coronavirus in Wuhan, China. Lancet. 2020;395 (10223):497-506. doi:10.1016/S0140-6736(20)30183-5

2. Pei X, Jiao X, Lu D, Qi D, Huang S, Li Z. How to face COVID-19 in ophthalmology practice. Med Hypothesis Discov Innov Ophthalmol. 2020;9(3):164-171. doi:10.51329/mehdiophthal1406

3. Chowell G, Abdirizak F, Lee S, et al. Transmission characteristics of MERS and SARS in the healthcare setting: a comparative study. BMC Med. 2015;13(1):210. doi:10.1186/s12916-015-0450-0

4. Schneiderman H. The Funduscopic Examination. In: Walker HK, Hall WD, Hurst JW, editors. Clinical Methods: The History, Physical, and Laboratory Examinations. 3rd ed. Boston: Butterworths; 1990. Chapter 117. Available from: https://www.ncbi. nlm.nih.gov/books/NBK221/. Accessed August 10, 2021.

5. McGrath D. EURETINA charts path through COVID-19 crisis. EURETINA-Brief. 2020;(210). Available at: https://brief.eure tina.org/2020/04. Accessed August 12, 2021.

6. Xu D, Starr MR, Boucher N, et al. Real-world vitreoretinal practice patterns during the 2020 COVID-19 pandemic: a nationwide, aggregated health record analysis. Curr Opin Ophthalmol. 2020;31 (5):427-434. doi:10.1097/ICU.0000000000000692

7. Eysenbach G. Improving the quality of web surveys: the checklist for reporting results of internet E-surveys (CHERRIES). $J$ Med Internet Res. 2004;6(3):e34. doi:10.2196/jmir.6.3.e34

8. Ankita, KA, Saxena SK: COVID-19: An Ophthalmological Update. Coronavirus Disease 2019 (COVID-19). Medical Virology: From Pathogenesis to Disease Control. Saxena S (ed): Springer, Singapore; 2020:81-93. doi:10.1007/978-981-15-4814-7_8

9. Papa RT, Daguman I, Ongkeko JM, Salongcay R, Santos-Rayos JJ, Uy CS. Evolving guidelines for retinal procedures during the COVID-19 pandemic: outpatient clinic; 2020. Available from: https:// drive.google.com/file/d/116VKQVCaKTr9GKCGcu0IGyP8bra4Rxsx/ view. Accessed August 10, 2021.

10. American Society of Retina Specialists. COVID-19: updates and resources; 2020. Available from: https://www.asrs.org/practice/asrsmember-alert-regarding-covid-19-pandemic. Accessed August 10, 2021. 
11. American Academy of Ophthalmology. Clinical coronavirus resources; 2020. Available from: https://www.aao.org/covid-19. Accessed August 10, 2021.

12. Smereka J, Szarpak L, Filipiak KJ. Modern medicine in COVID-19 era. Disaster Emerg Med J. 2020. doi:10.5603/DEMJ.a2020.0012

13. Sorbello M, El-Boghdadly K, Di Giacinto I, et al. The Italian coronavirus disease 2019 outbreak: recommendations from clinical practice. Anaesthesia. 2020;75(6):724-732. doi:10.1111/anae.15049

14. Bedford J, Enria D, Giesecke J, et al. COVID-19: towards controlling of a pandemic. Lancet. 2020;395(10229):1015-1018. doi:10.1016/ S0140-6736(20)30673-5
15. Chee R, Darwish D, Fernández-Vega Á, et al. Retinal telemedicine. Curr Ophthalmol Rep. 2018;6(1):36-45. doi:10.1007/s40135-0180161-8

16. Azarcon CP, Ranche FKT, Santiago DE. Tele-ophthalmology practices and attitudes in the Philippines in light of the COVID-19 pandemic: a Survey. Clin Ophthalmol. 2021;15:1239-1247. doi:10.2147/OPTH.S291790

17. Safadi K, Kruger JM, Chowers I, et al. Ophthalmology practice during the COVID-19 pandemic. BMJ Open Ophthalmol. 2020;5 (1):e000487. doi:10.1136/bmjophth-2020-000487

\section{Publish your work in this journal}

Clinical Ophthalmology is an international, peer-reviewed journal covering all subspecialties within ophthalmology. Key topics include: Optometry; Visual science; Pharmacology and drug therapy in eye diseases; Basic Sciences; Primary and Secondary eye care; Patient Safety and Quality of Care Improvements. This journal is indexed on PubMed

Submit your manuscript here: https://www.dovepress.com/clinical-ophthalmology-journal
Central and CAS, and is the official journal of The Society of Clinical Ophthalmology (SCO). The manuscript management system is completely online and includes a very quick and fair peer-review system, which is all easy to use. Visit http://www.dovepress.com/ testimonials.php to read real quotes from published authors. 